\title{
THE USE OF ANALYTICAL HIERARCHY PROCESS (AHP) IN PRODUCT DEVELOPMENT PROCESS
}

\author{
Mohd Azroy Mohd Razikin* \\ Universiti Teknikal Malaysia Melaka, \\ Melaka, Malaysia \\ E-mail: azroy.razikin@gmail.com \\ Hambali Arep @ Ariff \\ Universiti Teknikal Malaysia Melaka, \\ Melaka, Malaysia \\ E-mail: hambali@utem.edu.my \\ Ab Rahman Mahmood \\ Universiti Teknikal Malaysia Melaka, \\ Melaka, Malaysia \\ E-mail: abrahman@utem.edu.my \\ Isa Halim \\ Universiti Teknikal Malaysia Melaka, \\ Melaka, Malaysia \\ E-mail: $\underline{\text { isa@utem.edu.my }}$
}

\begin{abstract}
The use of the analytical hierarchy process (AHP) in the product development process was explored in this paper. AHP is a decision-making method has been widely used for more than 20 years recently and it has also been used in product development activities. Related articles around the years 2002 to 2012 were identified to review the implementation of the AHP methodology in product development activities. The use of AHP is not only limited to the AHP itself but can be integrated with other design tools. This paper shows the AHP applications and its integration in product development activities. The framework was developed to describe the relationship AHP with the other design tools in the product development activities. Therefore, it may be used to help decision makers to select the appropriate design tool in the area of product development which enhance the AHP applications in the product development activities.
\end{abstract}

Keywords: Analytical hierarchy process, Product development activities, Product design specification (PDS).

\section{Introduction}

Saaty (1980) developed AHP at the Wharton School of Business, where according to Ho (2007) the methodology of AHP was widely used by the decision makers to solve the problem on decision making in the last 20 years. AHP had been used by the decision makers in product development activities including customer need identification, determining product design specification (PDS) and design concept selection. AHP is also can be integrated with other design tools in product development activities, for example design for environment (DFE), design for manufacturing and assembly (DFMA), failure mode element analysis (FMEA), quality function deployment (QFD), etc.

\footnotetext{
${ }^{*}$ Corresponding author
} 
AHP allows the relationships of goal, objective, sub objective and alternative show as a hierarchical structure as depicted in Figure 1 in the decision making process. To achieve the goal in decision making, AHP is a compensatory methodology because it allows objective and sub objective to cooperate each other. Beside, every performance of alternative is compensated because the lack of an alternative which not respect to one or more objective can compensate with respect to another objective (Saaty, 1980).

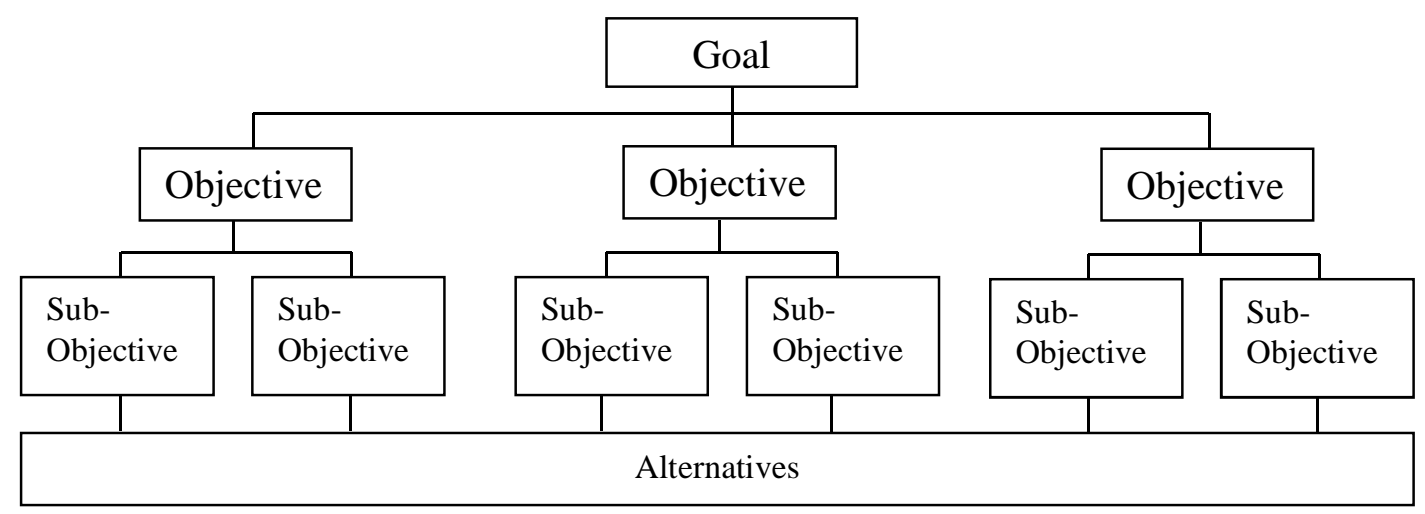

Figure 1. AHP hierarchy structure (Saaty, 1980).

\section{AHP approach in Product development activities.}

The applications of AHP in product development activities are discussed in this paper as depicted in Figure 3 and Table 1 to Table 6.

\subsection{The use of AHP in customer needs identification}

Form literature review, there are many papers have been discussed the use of AHP in customer needs identification. Hsiao (2002) used the AHP approaches to identify customer needs by integrating with QFD, FMEA and DFA in the development of new safe toys for children under the age of seven. Kwong and Bai (2003) also combined the method of AHP and QFD to identify customer need. In addition, fuzzy methods have been combined with the AHP method to improve the efficiency in determining the weight of QFD for the design of a new hair dryer. Integration of AHP and fuzzy methods has also been performed by Lin et al. (2008). They have developed a framework assisted with TOPSIS to determine the needs of customers in the product development activities for personal digital assistants (PDA). Same with Kwong and Bai (2003), Felice and Petrillo (2010) also use the integrated AHP and QFD to determine the needs of their customers in a case study. To demonstrate the approach, a case study of the production of ceramic materials has been illustrated. Table 1 shows the approaches of AHP in customer need identification for 2002 until 2010. It shows the integration of AHP and QFD are the most commonly used in customer need identification. 
Table 1. AHP to identify customer need.

\begin{tabular}{llll}
\hline No. & Approaches & Authors & Year \\
\hline 1 & QFD - FMEA - AHP - DFA & Hsiao & 2002 \\
2 & QFD - Fuzzy - AHP & Kwong and Bai & 2003 \\
3 & AHP - TOPSIS & Lin et al & 2008 \\
4 & QFD - AHP & Felice and Petrillo & 2010 \\
\hline
\end{tabular}

\subsection{The use of AHP in Product Design Specification (PDS)}

There are two of the requirements to be achieved for identifying the product design specification (PDS) are manufacturing and performance safety as shown in Figure 2 (Hurst, 1999) . Some application of AHP in PDS as discussed as below:

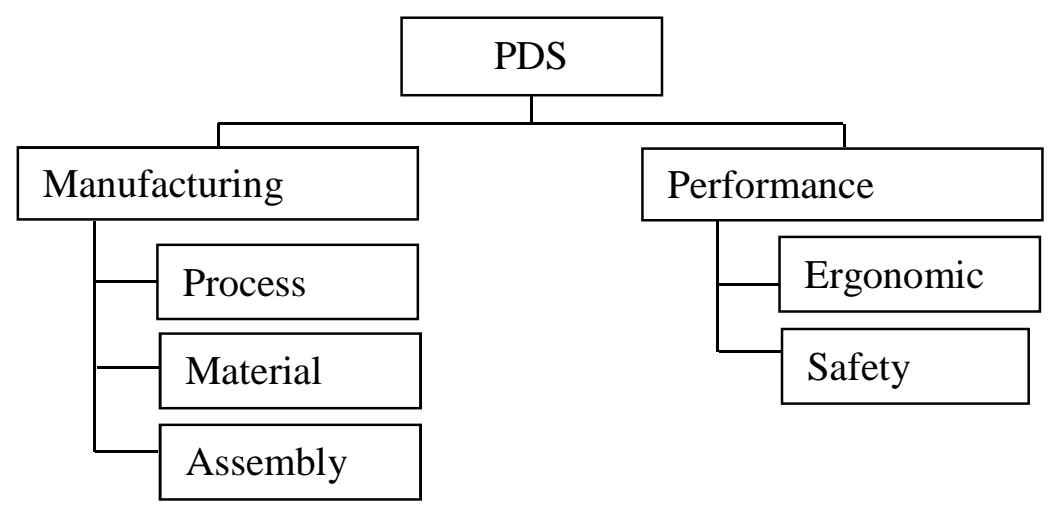

Figure 2. Product design specification (PDS) criteria.

\subsubsection{Manufacturing Process Selection}

Ravisankar et al. (2004) implemented AHP to select the best welding process the welding process to fabricate butt joints of high strength aluminum alloy AA 7075 grade. Computer aided integrated of QFD and Fuzzy-AHP framework was developed by Nagahunumaiah et al. (2007) for rapid tooling process selection. The framework was developed using Visual C++ Window environment. Duran and Aquilo (2008) proposed a Fuzzy-AHP based on software approach. They illustrated an example of CNC turning center process selected to demonstrate the approach. In addition, they proposed the approach of Matlab 7.0 software applications for calculation of fuzzy number due to a lot of time is needed for the calculation to find the final solution. Hambali et al. (2009) implemented the AHP to assist decision makers to select the best manufacturing process for composite automotive bumper beam. AHP concept was performed through utilizing Expert Choice software to choose the appropriate manufacturing process. Jafarian and Ahdath (2011) used combined fuzzy AHP - TOPSIS to get more appropriate and effective result to select the best welding process for pressure vessel production. Table 2 shows the approaches of AHP in manufacturing process selection from 2004 until 2011. It shows the approach of fuzzy and the computer aided tool was commonly integrated with AHP in manufacturing process selection. 
Table 2. AHP in manufacturing process selection.

\begin{tabular}{llll}
\hline No. & Approaches & Authors & Year \\
\hline 1 & AHP & Ravisankar et al. & 2004 \\
2 & Fuzzy - AHP - Visual C++ & Nagahunumaiah et al. & 2007 \\
3 & Fuzzy - TOPSIS - Math Lab 7.0 & Duran and Aquilo & 2008 \\
4 & AHP - Expert Choice & Hambali et al. & 2009 \\
5 & Fuzzy - AHP - TOPSIS & Jafarian - Vahdath & 2011 \\
\hline
\end{tabular}

\subsubsection{Material Selection}

Coa et al. (2006) developed the Integrated AHP and gray relation analysis (GRA) to supports the decision making in the material selection. This selection aims to choose the best material for the electronic device housing. Dweiri and Al-Oqla (2006) performed the AHP method through Expert Choice software application to determine the proper material for key manufacturing. Comparison of QFD and AHP approach in the selection of materials was done by Mayyas et al. (2011). Comparisons are made for the selection of materials in vehicle structures for automotive body in white (BIW) panels. Rohith et al. (2011) implemented AHP to select the best material for solar flat plat collector manufacturing. They perform the AHP without utilizing or integrating with any other design tool or computer aided application. Table 3 shows the use of AHP in material selection from 2006 until 2011. It shows the AHP not only performed by itself, but also can be integrated with others design tool for selection of proper materials.

Table 3. AHP in Material selection.

\begin{tabular}{llll}
\hline No. & Approaches & Authors & Year \\
\hline 1 & AHP - GRA - DFE & Cao et al. & 2006 \\
2 & AHP - Expert Choice & Dweiri and Al-Oqla & 2006 \\
3 & QFD - AHP & Mayyas et al. & 2011 \\
4 & AHP & Rohith et al. & 2011 \\
\hline
\end{tabular}

\subsubsection{Design for Assembly (DFA) and Design for manufacturing (DFM)}

Koganti et al. (2007) proposed the application of AHP for DFA in automotive component design and present a case study involving car front end component design. Ong et al. (2003) and Liu et al. (2008) proposed DFM evaluation system by formulating a set of fuzzy to make a connection on manufacturability Índice (MIS). Ong et al. (2003) used this approach to casting manufacturablity evaluation close tolerance air-cooling turbine blades. While Liu et al. (2008) using this approach to rotational part manufacturing. 
Table 4. AHP in DFA and DFM.

\begin{tabular}{lllc}
\hline No. & Approaches & Authors & Year \\
\hline 1 & AHP - DFA & Koganti et al. & 2007 \\
2 & Fuzzy - AHP - DFM & Ong et al. & 2003 \\
3 & Fuzzy - AHP - DFM & Liu et al. & 2008 \\
\hline
\end{tabular}

\subsubsection{Ergonomics and human safety}

Zhao et al. (2010) and Xihui et al. (2010) using the AHP method for the evaluation of ergonomics to match human and machine interface. Zhao et al. (2010) used the Delphi method and AHP together in designing the interface in space and Xihui et al. (2010) used this method in the selection of the best design for a control panel. Chosen of safety devices for product development was influenced by many factors including cost, effectiveness, reliability, risk of naturalization and others (Caputo et al., 2010). It leads to the contribution of the AHP method due to the multiple criteria decision making on the installation of safety device in machinery. Caputo et al. (2010) agreed that the AHP methodology can assist in the selection of safety devices for industrial machinery. The approaches of AHP in Ergonomic and human safety are illustrated in Table 5 .

Table 5. AHP in Ergonomics and human safety.

\begin{tabular}{lllc}
\hline No. & Approaches & Authors & Year \\
\hline 1 & Delphi - AHP & Zhao et al. & 2010 \\
2 & Fuzzy - AHP & Xiu et al. & 2010 \\
3 & AHP & Caputo et al. & 2012 \\
\hline
\end{tabular}

\subsection{Design concept selection}

Improper decision making at the early conceptual design stage would contribute the part to be redesigned or remanufacturing (Hambali et al., 2008). The use of AHP in the conceptual design stage is shown in Table 6. Boonkanit and Apikajornsin (2005) integrated the QFD, DFE and AHP methodology to select the best design of printed. The concept generation started with Quality Function Development for Environment (QFDE) to evaluate design requirement from customer and after that DFE was used to become the guideline to engineer for the green technology. Finally AHP was used to select an appropriate design. Hambali et al. (2008) used the AHP method to select the best design of wheelchair from eight design alternatives. The selection was performed by using AHP without integrating with any other design tool. Hambali et al. (2009) proposed a concept selection model called concurrent design concept selection and material selection (CDSMS) at the conceptual design stage using AHP. It uses to select the proper design concept and material for automotive composite component. Sarfanaz and Jenab (2012) proposed a model based on Fuzzy Analytical Hierarchy Process (FAHP). 
Table 6. AHP in Design concept selection.

\begin{tabular}{lllc}
\hline No. & Approaches & Authors & Year \\
\hline 1 & QFD - DFE - AHP & Boonkanit and Apikajornsin & 2005 \\
2 & AHP & Hambali et al. & 2008 \\
3 & AHP - CDSMS & Hambali et al. & 2009 \\
4 & Fuzzy - AHP & Sarfanaz and Jenab & 2012 \\
\hline
\end{tabular}

\subsection{Application AHP in Product Development activities}

Figure 3 shows the overall framework of AHP implementation in the product development activities. It includes with three main areas in product development activities namely, customer need identification, product design specification (PDS), and design concept selection. From PDS, it consists of five sub areas of product development activities including manufacturing process, material, design for manufacturing and assembly (DFMA), ergonomics and safety. Each area provides the application from the product development activities. Even though AHP can be integrated with other design tools but there is no research carried out on the integrated AHP with the failure mode effect critical analysis (FMECA) in the product design activities.

\section{Conclusion}

The application of AHP was discussed in this paper. It shows that AHP can be integrated with other design tools in product development activities such as the design for environment (DFE), design for manufacturing and assembly (DFMA), quality function deployment (QFD), etc. The integrated AHP was developed in the early stages of product development to avoid loss of profit owing to remanufacturing or redesign activities. From the literature review, there is no integration between AHP and FMECA that can be proposed as one the decision making approach in the product development activities.

\section{Acknowledgement}

The author wish thank to Universiti Teknikal Malaysia Melaka (UTeM) for supporting this paper. Special thanks to knowledge transfer program (KTP) grant, GLuar/2012/FKP (2) /G00011 for financial support.

\section{REFERENCES}

Caputo, A.C., Pelagagge \& Paolo Salini, P. (2012). AHP-based methodology for selecting safety devices of industrial machinery. Safety Science 53 (2013). 202-218.

Cao, H. J., Liu F., Li, C.B. \& Liu, C., (2006). An Integrated Method for Product Material Selection Considering Environmental Factors and a Case Study. Materials Science Forum, 532-533, 1032

Duran, O. \& Aguilo, J. (2008). Computer-aided machine-tool selection based on a Fuzzy-AHP approach. Expert Systems with Applications 34 (2008), 1787-1794.

Dweiri, F. \& Al-Oqla, F.M. (2006). Material selection using analytical hierarchy process. Int. J. Computer Applications in Technology, Vol. 26, No. 4, pp. 182-189. 


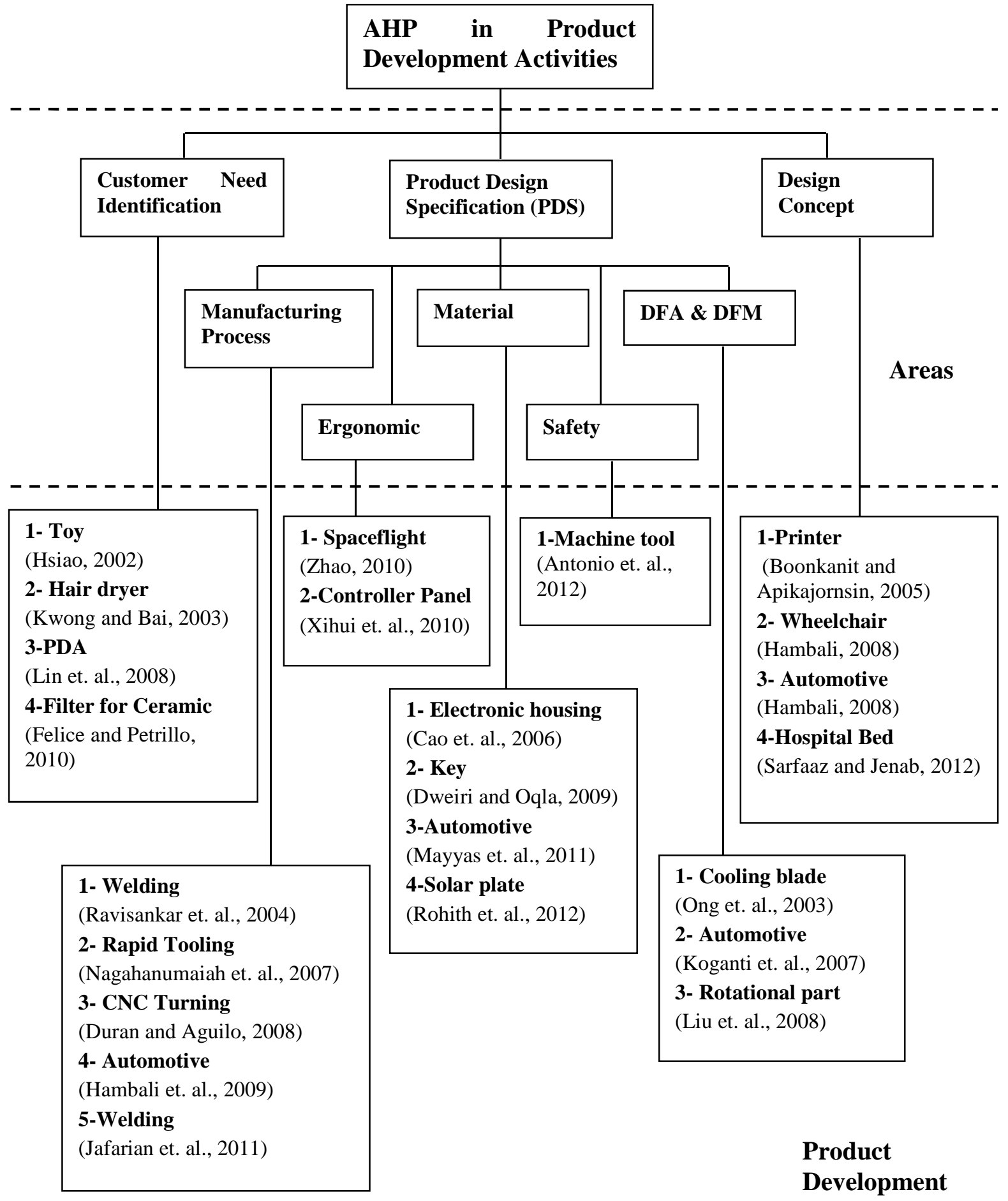

Figure 3. Application of AHP in Product Development activities 
Felice, F.D. \& Petrillo, A. (2010). A multiple choice decision analysis: an integrated QFD - AHP model for the assessment of customer needs. International Journal of Engineering, Science and Technology (2010), Vol. 2, No. 9,25-38.

Hambali, A., Sapuan, S.M., Ismail, N. \& Nukman, Y. (2008). Use of Analytical Hierarchy Process (AHP) for Selecting the best Design Concept. Jurnal Teknologi, 49 (A) Dis. 2008: 1-18

Hambali, A., Sapuan, S.M., Ismail, N. \& Nukman, Y. (2009). Application of analytical hierarchy process in the design concept selection of automotive composite bumper beam during the conceptual design stage. Scientific Research and Essay Vol. 4 (4), April (2009) . 198-211

Hambali, A., Sapuan, S.M, Ismail, N. \& Nukman, Y. (2009). Composite manufacturing process selection using analytical hierarchy process. International Journal of Mechanical and Materials Engineering (IJMME), Vol. 4 (2009), No. 1, 49 -61.

Ho, W. (2007) Integrated analytic hierarchy process and its applications - A literature review. European Journal of Operational Research $x x x$ (2007) $x x x-x x x$

Hsiao, S.W. (2002). Concurrent design method for developing a new product. International Journal of Industrial Ergonomics 29 (2002,) 41-55

Hurst K. S., 1999. Engineering Design Principle. New York, John Wiley and Son Inc.

Jafarian, M. \& Vahdat, S.E. (2011). A fuzzy multi-attribute approach to select the welding process at high pressure vessel manufacturing. Journal of Manufacturing Processes 14 (2012,) 250-256.

Kwong, C.K \& Bai ,H. (2003). Determining the importance weights for the customer requirements in QFD using a fuzzy AHP with an extent analysis approach. IIE Transactions, 35 (7).

Koganti, R., Zaluzec, M., Chen, M., \& Defersha, F. (2007). Design for Assembly: An AHP Approach for Automotive Front End Component Design Evaluation, SAE Technical Paper 2007-01-0522, 2007.

Liu, H.G., Mo, R., Fan, Q.M., Chang, Z.Y., \& Zhao, Y. (2008). A Fuzzy Set AHP-based DFM Tool Under Concurrent Engineering Environment. Applied Mechanics and Materials Vols. 10-12 (2008) pp 145-149.

Lin, M.C., Wang, C.C, Chen, M.S. \& Chang, C.A. (2003). Using AHP and TOPSIS approaches in customer-driven product design process. Computers in Industry 59 (2008), 17-31

Mayyas, A., Qin Shen, Abdelhamid, M., Dongri Shan, Qattawi, A. \& Omar, M. (2011). Using Quality Function Deployment and Analytical Hierarchy Process for material selection of Body-In-White. Materials and Design 32 (2011). 2771-2782.

Nagahanumaiah, Subburaj, K. \& Ravi, B. (2007). Computer aided rapid tooling process selection and manufacturability evaluation for injection mold development. Computers in Industry xxx (2007) xxx-xxx.

Ong, S.K., Sun, M.J., \& Nee, A.Y.C, (2003). A fuzzy set AHP-based DFM tool for rotational parts. Journal of Materials Processing Technology 138 (2003), 223-230. 
Ravisankar,V., Balasubramanian,V. \& Muralidharan, C .(2004). Selection of welding process to fabricate butt joints of high strength aluminium alloys using analytic hierarchic process. Materials and Design 27 (2006), 373-380.

Rohith, B.J, Venkataramaiah, P. \& MohanaReddy, P. (2012). Material selection for solar flat plate collectors using AHP. Research and Applications (IJERA) Vol. 2, Issue 2,Mar-Apr (2012), 1181-1185.

Saaty, T. L. (1980). The Analytical Hierarchy Process. New York, McGraw Hill. RWS

Sarfaraz, A., \& Jenab, K. (2012). A Fuzzy Conceptual Design Selection Model Considering Conflict Resolution. IACSIT International Journal of Engineering and Technology, Vol. 4, No. 1, February 2012

Xihui, Y., Dinghua, Z., Changde, L. \& Suihuai, Y. (2010). Design of Controller Panel Based on Ergonomics. IEEE.

Zhao, Y., Ding, L., Xu Li, D., Wei \& Qie, W. (2010). A ergonomics evaluation hierarchy for the typical manually controlled devices in spaceflight. Industrial Engineering and Engineering Management (IEEM), 2010 IEEE International Conference 